\title{
News You Can Use
}

\section{Kevin Allan Johnston University of Cape Town, Cape Town, South Africa}

Kevin.johnston@uct.ac.za

\begin{abstract}
Susan Benvenuti, University of Witwatersrand, Johannesburg, South Africa
\end{abstract}

\author{
Susan.Benvenuti@wits.ac.za
}

\begin{abstract}
It is widely accepted that assessment determines learning: what is learnt, how the learning takes place, the extent to which the learning is retained, and the extent to which that learning can be further developed or applied (Biggs, 2003; Boud, Cohen, \& Sampson, 1999; Entwistle \& Entwistle, 1997; Rowntree, 1992).

This paper examines an assessment intervention undertaken independently by two South African Universities in their first year Information Systems Courses, aimed at improving both the learning of content and the development of academic and career skills, within the constraints of curriculum, large classes and under-preparedness of students. Departing from a similar concept, the two universities designed and implemented the assessment tasks independently, with each experiencing different successes and challenges. Representing a first cycle in an Action Research study, the underlying rationale behind the interventions is presented, together with a detailed analysis of the two case studies and their shared lessons learned from the experience.
\end{abstract}

Keywords: assessment, large classes, academic literacy, student engagement, newspaper.

\section{Introduction}

In common with many countries throughout the world, South Africa faces a shortage of graduates and skills in the ICT field. In response to this shortage as well as a decline in student numbers in ICT related studies, the South African Minister of Education, Naledi Pandor initiated a National Colloquium on Information and Communication Technology Education and Training and the Production of Graduates in March 2007 ("ICT skills in South Africa," 2007). The colloquium focused on graduate shortages in the ICT field, and possible steps that might be taken to reduce these shortages, highlighting the essential role played by tertiary institutions in this regard.

This paper examines the experience of two South African universities in adopting an innovative assessment approach aimed at overcoming some of the identified problems and challenges facing universities in South Africa in respond-

Material published as part of this publication, either on-line or in print, is copyrighted by the Informing Science Institute. Permission to make digital or paper copy of part or all of these works for personal or classroom use is granted without fee provided that the copies are not made or distributed for profit or commercial advantage AND that copies 1) bear this notice in full and 2) give the full citation on the first page. It is permissible to abstract these works so long as credit is given. To copy in all other cases or to republish or to post on a server or to redistribute to lists requires specific permission and payment of a fee. Contact Publisher@InformingScience.org to request redistribution permission. ing to the ICT skills shortage. It begins by identifying some of the problems and challenges faced, and then briefly explain the background and rationale behind the assessment innovation and research approach. Thereafter a more detailed examination of the experiences of the two universities is given, highlighting the differences in focus and implementation of the original concept. The 
paper concludes with some discussion on the lessons learned and the proposed changes in the assessment tasks for the next cohorts of students at the two universities.

\section{Background}

The University of Cape Town (UCT) and the University of the Witwatersrand (WITS) are recognised as two of South Africa's premier universities, attracting top students from around the country. As politically active universities during the apartheid struggle and with an ongoing focus on redressing the problems of the past, the universities are also both committed to accepting promising students from backgrounds which have not sufficiently prepared them for the academic demands of university studies.

During the annual examination moderation process at the end of the 2006 academic year, academics from the two universities were discussing some of the problems and challenges that they faced working with students in the first year courses. Issues such as large classes, academic literacy, curriculum coverage, understanding, and lack of student engagement were found to be common problems and challenges.

Talk was based on a constructivist learning environment (learner-centred model) (Ng'ambi \& Johnston, 2005). In a constructivist learning environment the lecturers role changes from being a source of knowledge to facilitating learning. Crotty $(1998$, p. 58) used the term constructivism to refer to the epistemological considerations focusing exclusively on 'the meaning-making activity of the individual mind.' Karagiorgi and Symeou (2005, p. 24) asserted, “... in a world of instant information, constructivism can become a guiding theoretical foundation and provide a theory of cognitive growth and learning that can be applied to several learning goals." In the learnercentred model, "knowledge for constructivism cannot be imposed or transferred intact from the mind of one knower to the mind of another" (Karagiorgi \& Symeou, 2005, p. 18).

Based on some research relating to the first year courses at both universities, ideas were shared and the idea of the students developing a collaborative 'newspaper' which covered all or most aspects of the course was first mooted by Susan Benvenuti of WITS. It was decided that each institution would design and create such a 'newspaper' without further collaboration or discussion and that the results would be reviewed at the end of 2007.

\section{Problems and Challenges}

Academics from both WITS and UCT faced similar problems and challenges relating to teaching and assessing first year introductory IS courses:

- Large Classes: both universities have several large classes taking first year IS, with some students doing only the compulsory introductory course, and others going on to major in the subject. Large classes can present many problems and challenges which are often exacerbated by the fact that most of these large classes are first year students who come from small, school classes where they were known by the teachers and understood what was expected from them (Ward \& Jenkins, 1992). Students in the Ward and Jenkins (1992) study commented on feeling overwhelmed, anonymous, disorganised and unprepared.

Lecturers working with large classes have challenges including forming relationships with students or classes, organisation, administration loads, teaching approaches and assessment (Gibbs \& Jenkins, 1992). Large numbers make it difficult for lecturers to give and receive feedback, as well as to encourage deeper learning through teaching and learning activities and assessment approaches that facilitate engagement with content knowledge. Furthermore, Gibbs and Jenkins (1992) point out that not only are the numbers growing, but within the larger groups there is more variety in ability and background. 
- Academic Literacy - "The Gap": most students entering first year university courses encounter some level of difficulty in adjusting to the specific demands of academic literacy needed at university level. Craig (1996), Mumba, Rollnick, and White (2002), and Alfred, Dison, and Hagemeier (2000) acknowledge the existence of a "gap" between what is expected of students by lecturers and the general reality of what they can or do deliver.

Many students in the IS courses under discussion have difficulty with independent reading and research, and display low levels of information literacy. Students find difficulty in selecting and analysing information appropriately, and seem unable to synthesise effectively and write with appropriate academic style. These problems are compounded when they occur in large classes, with under-prepared students, and with students studying in their second or even third or fourth language. Many of these problems only come to light in later years of study when smaller classes allow for the types of assessment tasks that require these skills.

- Curriculum Coverage: As with many first year introductory courses, there are complicated debates around curriculum, focusing on the breadth and depth of coverage of a growing field. Academics working with students in later years of study have particular requirements, and consideration must also be given to students who will only complete one year of study in IS. Difficulties also arise with some first year students starting with little or no previous exposure to computers and technology, while others have extensive previous exposure and experience. In addition many courses include the teaching of computer literacy and productivity tools such as spreadsheets, word processors and databases.

- Student Engagement: Highlighted by research at UCT (Johnston, Turner, Salie, \& Goosen, 2006; Ng'ambi \& Johnston, 2005), and noted through informal observation at WITS, many students were found to not engage sufficiently with the IS courses. Many students do not attend lectures or tutorial sessions, and are often unwilling or unable to take responsibility for their learning and development. Many of the students are passive participants and adopt a largely surface approach to their learning. Students requested supplementary notes in addition to the text books (Johnston et al., 2006).

Based on these problems and challenges, and the impact these have on pass rates and hence number of ICT graduates, the assessment intervention below was conceptualised, designed and implemented for the 2007 academic year at both UCT and WITS.

\section{The Assessment Intervention - Rationale and Approach}

It is often asserted that assessment determines learning: what is learnt, how the learning takes place, the extent to which the learning is retained, and the extent to which that learning can be further developed or applied (Biggs, 2003; Boud et al., 1999; Entwistle \& Entwistle, 1997; Ramsden, 1992; Rowntree, 1992).

Ramsden (1992) states that "the most significant single influence on students' learning is their perception of assessment" and that "from our students' points of view, assessment always defines the actual curriculum." Biggs (2003) defines this effect as "backwash", with assessment determining the learning outcomes of the students, rather than the desired outcomes, curriculum and teaching activities as envisaged by the lecturer. While this might often result in a negative outcome, Biggs (2003) suggests that awareness of this backwash effect can be used to influence or guide the learning activities of students. Shuell (1986) said:

"If students are to learn desired outcomes in a reasonably effective manner, then the teacher's fundamental task is to get students to engage in learning activities that are likely to result in their achieving those outcomes ... It is helpful to remember that what the stu- 
dent does is actually more important in determining what is learned than what the teacher does."

With this in mind, assessment was targeted as a means by which to address some of the identified challenges above, as well as to enable measurement of student improvement and achievement.

The proposed assessment task was for collaborative student teams to create IT focused publications (newspapers or magazines) which would cover all or most aspects of the course curriculum. Taking this concept as a starting point, the IS departments of two universities then worked separately, defining the specific assessment roles, objectives and outcomes to suit their particular situations. The approaches taken, together with each department's analysis and evaluation of the assessment intervention, are described in some detail in this paper.

\section{Research Design}

Action research is practical means for academics to uncover some of the complexities of the teaching process in order to improve the learning process (Altrichter, Posch, \& Somekh, 1993). Action Research is most appropriate when implementing change (Sekaran, 2003) as both courses were doing. In Action Research, a researcher begins with an identified problem, then gathers data to provide a possible solution, implements the solution, and then evaluates the effects. "Action Research is a constantly evolving project with interplay among problem, solution, effects or consequences, and new solution" (Sekaran, 2003, p36).

This paper looks at the action research cycle after the implementation of a first solution to the identified problems and challenges of each course, and presents an evaluation of the success of the task in each case, together with proposed changes and refinements to the assessment task.

\section{The UCT Scenario}

\section{Background to IS at UCT}

UCT ran three first year Information System (IS) classes in 2007; INF1002F in the first semester with 698 students, INF1002H was run over 12 months for Academic Development Programme with 68 students, and INF1002S ran in the second semester with 308 students.

All three courses followed the same curriculum with the same lecturers and had similar deliverables. One of the deliverables in 2007 was a Literature Review [Task 6]. Students formed groups of 5 for a series of deliverables, one of which was a literature review on an aspect of IS. Hand in dates depended on topic allocated.

\section{Problems}

Students at UCT were increasingly disengaging themselves from IS courses (in particular the first year course), this was reflected in decreasing lecture attendance and in student evaluations of the courses (Johnston et al., 2006). Falling IS student numbers is a national and international issue.

\section{Data Gathering}

In November 2006 questionnaires and small focus groups were used at UCT to identify issues among current and past IS students (Johnston et al., 2006). Some of the problems highlighted were:

- Several students did not comprehend what an information system was until their third year of study. 
- Students were unable to tie the theoretical content of the course to the practical.

- Several students from disadvantaged educational backgrounds were most affected.

- The course textbook was poorly received by the students. Many found the text tedious and difficult to read.

In addition other problems such as large classes in large lecture venues, scheduling difficulties regarding tutorials and workshops, student diversity and the split between theory and practicals were highlighted. These problems are fairly common (Tolhurst \& Baker, 2003).

\section{Possible Solutions}

Although a wide range of possible solutions was developed (including a total redesign of the course, use of a new textbook, use of different more experienced lecturers, a marketing campaign, increased collaboration with feeder institutions, increased use of technology), the one focused on in this research was how to supplement the text book with readable relevant and useful text, while simultaneously developing the students.

An IS publication developed by the students was seen as a vehicle through which to create this text.

\section{Design of UCT Task}

Each first year IS student group was assigned a topic and a hand in date by the course convenor by the end of week 2 of the course. Groups were required to submit a literature review (maximum 6 pages) in Word format (with photographs or diagrams) on a topic allocated to Turnitin.com by a certain date. Turnitin.com was used to discourage and prevent plagiarism. Students were given a lecture and a handout on how to set about doing a literature review, referencing, plagiarism, how to use Turnitin.com. The literature review contributed $8 \%$ of each student's final mark.

Each group was assigned a topic which was linked to a chapter of the pre-scribed text book. The due date for each Literature review was set to be at least 7 days after the topic was covered in lectures. Some of the topics from the first three chapters (1.1 indicated first article from chapter 1 and so on) of Benson and Standing (2005) included:

1.1 What is a system? Systems Thinking

1.2 What is an Information System?

1.3 Data, information and knowledge (KM)

1.4 Technology and business trends

1.5 Understanding Organisations (structure, defined, depicted, maintained, SOP)

1.6 Direct and indirect benefits of Information Systems

1.7 What is a Business Process?

2.1. Types of computers in current use

2.2. The architecture of the modern computer

2.3. How to buy a PC

2.4. Comparing Internet connection options suitable for home use.

3.1. Types of software in current use

3.2. Nature of competition in software industry

3.3. Common horizontal applications

3.4. Packaged, customised and custom-built software 
3.5. Relationship between systems software, applications software and hardware

3.6. Open source vs proprietary software

An editorial board of Masters Students was appointed to mark and correct the literature reviews and convert them into newspaper type articles. The department then published all the papers as an electronic newspaper at the end of the semester which was in effect a summary of the course. Students were encouraged to use the newspaper as a learning tool.

\section{Implementing the Assessment Tasks}

Students were required to form groups of 5 for a variety of tasks, some practical and some theoretical by the end of the first week of term. Students who were unable or could not form groups were assisted and placed in groups by staff. Details of the groups (and their assigned tasks and due dates) were posted on noticeboards and on an online Student Management System. Each group was assigned a literature review topic from a chapter of the pre-scribed text book (Benson $\&$ Standing, 2005) with a due date at least 7 days after the topic was covered in lectures.

Students submitted their literature reviews to Turnitin.com on or before the due date, late submissions were penalised.

A Masters student was then assigned to mark each literature review, and students were handed back the marked work with comments. A second Masters student then edited the literature review, correcting mistakes, and removing citations. The edited review was then pasted into an electronic 'newspaper' which was titled 'Eye-S'. It was hoped that each review would include the groups name or student names as a by-line so students could identify with the work.

\section{Successes and Challenges}

Generally students found the task challenging and interesting, however far too many (19\% in the first (F) semester course, $6 \%$ in the whole year course $(\mathrm{H})$, and $2 \%$ in the second $(\mathrm{S})$ semester course) opted not to do the task and to forfeit the $8 \%$. The Masters students had to write up papers for the missing articles for the F newspaper, articles from the F newspaper were used to fill in gaps in both the $\mathrm{H}$ and $\mathrm{S}$ newspapers.

The averages varied across the three courses, with the highest (57\%) being in the second semester course, the F course average was $46 \%$ and the $\mathrm{H}$ course $39 \%$. This could possibly be because the $\mathrm{S}$ course students were more aware of what was expected as they could communicate with the $\mathrm{F}$ course students. For many of the $\mathrm{H}$ course students, English is their second language and this may explain their lower marks. Top marks were $84 \%$ achieved by a group in the F course, $82 \%$ in the $\mathrm{S}$ course, and $64 \%$ in the $\mathrm{H}$ course.

The first newspaper (F course) appeared to have more added material from the Masters students such as jokes and fake advertisements, this could be due to increased pressure on the Masters students towards the end of the academic year.

Students did download the newspapers (average was 76\%), but we cannot be sure how useful they found the newspapers as this question was not asked.

\section{Lessons Learned - Feedback}

Marking and then editing literature reviews takes a huge amount of time with such large student groups, and it was decided to reduce the number of pages required from 6 to 4 in future. UCT needs a mechanism to assess if students found the task of researching and writing the literature reviews beneficial, and if the newspaper was useful as a course overview. UCT learned lessons 
from WITS, these included stating the objectives clearly, and allocating one chapter to a group of students, and possibly including an empirical research topic in each group.

\section{The WITS Scenario}

\section{Background to IS at WITS}

Information Systems forms part of the School of Economic and Business Sciences in the Faculty of Commerce, Law and Management. Students either take IS 1 as the first course of an intended major in IS, or as a compulsory single semester course required for all BCom Students. Classes can be very large with the total number of IS 1 students normally expected to be anything between 500 and 800 students.

\section{Problems and Challenges}

Further to the earlier discussion of shared problems and challenges, WITS focussed on designing an assessment task that would help to address issues relating to large classes, academic literacy and student engagement. In contrast to the UCT approach, curriculum coverage was not focussed on during the design of the assessment task.

As stated earlier, large classes provide many challenges in terms of both teaching and assessment. Aside from the issues raised earlier, a cause of major concern at WITS was that the majority of assessment tasks used in the IS 1 classes were summative in nature, and designed to help alleviate time spent marking. This meant that most of the assessment tasks relating to content or theory knowledge were tests or exams, and contained largely multiple choice or short answer questions. Analysis of these assessment tasks found that cognitive demands were lower than desired, and that students were neither encouraged to develop sufficient depth in learning or able to demonstrate it should it exist. As Lohman (1993) pointed out, MCQ's are misleading to both students and academics, with students viewing all knowledge as facts, unable to discern concepts and principles from facts, or "main ideas from details" as everything is worth the same one mark. Furthermore, there is no requirement for students to attempt to form a conceptual picture of the knowledge, so they do not even realise that it can or should be attempted.

\section{Design and Implementation of WITS task}

The challenge was therefore to design an assessment task that would encourage student engagement in the course, support the development of academic and information literacy, and allow for the development of more depth in discipline related knowledge. Furthermore, the task should also meet the accepted criteria of assessment in being valid, reliable and useable or manageable.

The IT Publication was specified as a collaborative team project (consisting of 9 to 12 members) in which each member of the team would write/contribute an article on any IT related topic which would then be included in a team publication. While each student was expected to work on their article independently, the team was required to work together to produce a single publication containing all the articles, along with covers, adverts, tables of content, etc. In addition to the articles, each team was expected to conduct and include the results of an IT related survey. Teams had to plan their publication in advance and were required to submit an "Editorial Board Report" in which they included their proposed publication title, team members and article "area" (software, hardware, innovation, etc.), as well as the questions for their IT survey.

The assessment task outline gave students details of what was required in terms of content and submission requirements, as well as the objectives of the task. The objectives given were as follows: 
The learning objectives are to:

- develop research skills

- $\quad$ develop writing skills

- develop the skill of synthesising information

- develop team work skills

- demonstrate creativity

- $\quad$ stimulate interest in new and exciting technology

- $\quad$ expose you to career and employment opportunities

- broaden your general knowledge of IS and IT

As well as

- $\quad$ to get good marks

- $\quad$ and last, but not least, to have fun!

No detailed specifications were given as to the content or structure of the individual articles, and no detailed criteria provided as to how they would be assessed or marked.

\section{Successes and Challenges}

The IT Publication was hailed by the majority of the students as "the best part of the course" and described as being "fun to do", "interesting", "stimulating" and "allowed us to be creative and express ourselves". Lecturers were delighted by the motivation and of the students, their engagement with the task, and the overall quality of the publications from a design and presentation point of view. It was seen as an excellent assignment through which to develop, demonstrate, and assess skills in word-processing, spreadsheet and publication software, all part of the skills and literacy aspect of the course.

On the negative side, some student teams complained of lack of effort and contribution, with several of the publications being submitted with missing articles or notes complaining of non participation of individuals.

From a lecturer and assessor point of view, the negative aspects revolved around the actual content of the student articles. It was very clear from the majority of the articles received that students neither understood what was required in writing an article, nor had many demonstrated any evidence of academic literacy. The articles in the main were rambling strings of facts, with little evidence of understanding of structure, argument, summary or conclusion. Most students had used only one source for their article, and these sources were often ill-chosen. Plagiarism was also rife.

From a marking or assessment point of view, the load was fairly heavy, with each publication taking between 45-60 minutes to mark. Marking criteria had not been set or communicated to the students or markers prior to assessment.

\section{Lessons Learned - Analysis and Task Redesign}

Looking at the assessment task from an overall perspective, the lecturers involved viewed it as having the potential to both develop and assess students across a broad spectrum involving both general academic, and discipline specific skills, principles and concepts. It would however need a major redesign in order to deliver on its potential. 
The first decision made was to keep the focus on the above mentioned skills, rather than to use the task to teach or assess content knowledge. It was however agreed that these skills would be further enhanced by being developed within the context of the discipline in which they would be used.

The objectives of the task were also revisited, and it was agreed that two major problems needed to be resolved. Firstly, the objectives relating to the development of academic and information literacy needed to be fore-grounded, and students needed to be given more guidance in what was required and expected. Rust, Price and O'Donovan (2003) report that students' learning and long term uptake is greatly improved by developing their understanding of both assessment criteria and the assessment process. In particular, they develop the students' ability to mark each other's work, thereby enhancing their understanding of what is required and allowing them to improve their own work. In the redesign of the task, students will be given the detailed assessment criteria in the form of a rubric, and will also be expected to work in pairs to edit and provide feedback on, draft versions of the individual articles. This also provides some feedback to students in an otherwise summative assessment task. The UCT lesson has taught us that the workload involved in editing these publications will not allow for submitting both drafts and final publications.

The second major redesign challenge arises out of the realisation that the objectives of the task encompass both products (the publication) and processes (team work, editing and feedback, project management, etc.). While it is relatively easy to assess the product, we had no criteria or tool for measuring the processes, most of which include vital disciplinary skills. As students tend to focus on what is assessed and thereby given value by lecturers, it was decided that a means by which to assess the process needed to be found. As this poses complications, it has been proposed that students submit a brief reflective piece of writing that comments on specific skills or principles that we wish to develop during this task. This demonstrates to the students that these skills and principles are deemed important by the lecturers, and furthermore begins to develop students' meta-cognitive knowledge as reflective learners.

Several other small issues arose around the publications including lack of relevance of articles, poorly designed surveys, etc. In order to try to address these issues, the planning stage of the publication will require a more in-depth submission with tutor facilitated guidance and feedback.

The article length will also be carefully specified and more guidance given around a required structure and genre. This should improve both the quality of the articles and reduce the time required for marking them.

The overwhelming view however remains that the IT Publication has the potential to be a value tool for both the development and assessment of important generic academic and discipline specific skills and principles.

\section{Conclusion}

Universities in South Africa face many similar issues in teaching first year IS such as large classes, low academic literacy, curriculum problems and student engagement. In discussions between academics from two South African universities an idea was born to set students a writing assessment in the form of a 'newspaper' which students could use to supplement study material.

The two universities approached the idea differently and without further consultation. Although the approached differed, similar outcomes were observed. Students at both universities found the task challenging and interesting, there were students who either did not participate or did not participate fully. Marking and assessment presented a huge time consuming challenge, and several of the articles were sub-standard. 
Both universities are going to modify their approaches based on own lessons learned, as well as lessons learned from each other, so the second cycle in the Action research will continue.

\section{Recommendations for Further Research}

More detailed post experience evaluation from student's perspective should be carried out. The effects of gender, schooling, and home language within the population sample could be examined, as well as correlation of mark obtained to final mark obtained.

\section{References}

Alfred, L., Dison, L., \& Hagemeier, L. (2000). Developing a sociology foundation course: An analysis of principles, methods, and materials. South African Journal of Higher Education, 14(3), 112-119.

Altrichter, H., Posch, P., \& Somekh, B. (1993). An introduction to the methods of action research. Routledge.

Benson, S., \& Standing, C. (2005). Information systems: A business approach. Australia: John Wiley \& Sons.

Biggs, J. (2003). Teaching for quality learning at university (2nd ed.). The Society for Research into Higher Education \& Open University Press.

Boud D., Cohen, R., \& Sampson, J. (1999). Peer learning and assessment. Assessment and Evaluation in Higher Education, 24(4), 413 - 426.

Craig, A. (1996). Education for all. South African Journal of Higher Education, 10(2), 47-55.

Crotty, M. (1998). The foundations of social research: Meaning and perspective in research process. Australia: Allen \& Unwin.

Entwistle, N., \& Entwistle, A. (1997). Revision and the experience of understanding. In F. Marton, D. Hounsell, \& N. Entwistle (Eds), The experience of learning. Edinburgh: Scottish Universities Press.

Gibbs, G., \& Jenkins, A. (1992). An introduction: The context of changes in class size. In G. Gibbs \& A. Jenkins (Eds), Teaching large classes in higher education: How to maintain quality with reduced resources (Chapter 1, pp. 11-22). London: Kogan Page.

ICT skills in South Africa. (2007). National colloquium on information and communication technology education and training and the production of graduates, held on Monday 19 March 2007. Available at http://www.cs.ru.ac.za/ictskills/

Johnston, K. A., Turner, N., Salie, R., \& Goosen, M. (2006). An investigation into what IS Students want from lectures. Conference on Information Technology in Tertiary Education (CITTE), Pretoria, ISBN 0-620-36564-1, http://citte2006.cut.ac.za

Karagiorgi, Y., \& Symeou, L. (2005). Translating constructivism into instructional design: Potential and limitations. Educational Technology \& Society, 8(1), 17-27.

Lohman, D. F. (1993). Teaching and testing to develop fluid abilities, Educational Researcher, 22 (7), $12-$ 23.

Mumba, F. K., Rollnick, M., \& White, M. (2002). How wide is the gap between high school and first-year chemistry at the University of the Witwatersrand? South African Journal of Higher Education, 16(3), 148-156.

Ng'ambi, D., \& Johnston, K. A. (2005). An ICT-mediated constructivist approach for increasing academic support and teaching critical thinking skills. Journal of Educational Technology \& Society, 244-253.

Ramsden, P. (1992). Learning to teach in higher education. London and New York: Routeledge.

Rountree, D. (1987). Assessing students: How shall we know them? London: Kogan Page 
Rust, C., Price, M., \& O’Donovan, B. (2003). Improving students' learning by developing their understanding of assessment criteria and processes. Assessment and Evaluation in Higher Education, 28(2), 148164.

Sekaran, U. (2003). Research methods for business. John Wiley \& Sons.

Shuell, T. J. (1986). Cognitive conceptions of learning. Review of Educational Research, 56, 411-436.

Tolhurst, D., \& Baker, B. (2003). A new approach to a first year undergraduate information systems. Australasian Computing Education Conference (ACE2003), Adelaide, Australia.

Ward, A., \& Jenkins, A. (1992). The problems of learning and teaching in large classes. In G. Gibbs \& A. Jenkins (Eds), Teaching large classes in higher education: How to maintain quality with reduced resources (Chapter 2, pp. 23-36). London: Kogan Page.

\section{Biographies}

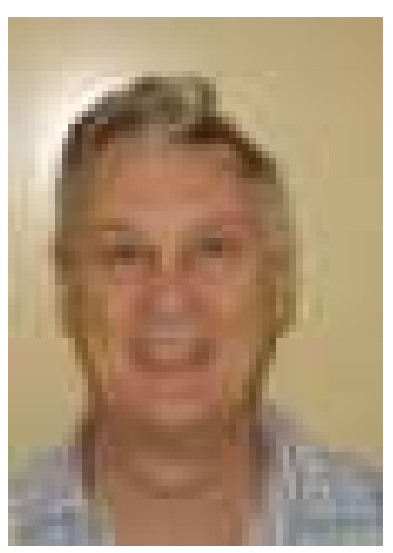

Kevin Johnston is currently a senior lecturer and Head of Department of the Department of Information Systems at the University of Cape Town (UCT), South Africa. He taught Mathematics \& Science at High Schools, before working for 24 years in IS industry for companies such as Wilson-Rowntree, De Beers, Liberty Life, Lifegro (Legal \& General Volkskas) and BoE. Kevin joined UCT in 2001 as Senior Lecturer in the Department of Information Systems. His main areas of interest are ICT Management and Project Management, and he has presented papers at conferences in Africa, Americas, Asia, and Europe. .

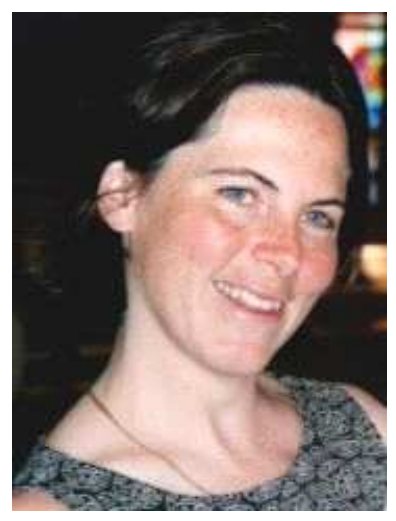

Susan Benvenuti is currently a lecturer in Information Systems at the University of the Witwatersrand (WITS), South Africa. A member of the IS Department at WITS since 2001, she has been lecturing for over 10 years, having worked in the IT industry for IBM prior to that. She has lived, worked and travelled in Africa, Asia, Europe and the USA. Her research interests focus largely on IT/IS Education, and she is part of a multi-disciplinary, university-wide research group focusing 